\title{
Management of a transverse vaginal septum complicated with hematocolpos in an adolescent girl: a case report
}

\author{
Kamal el Moussaoui ${ }^{1}$, AMINA LAKHDAR ${ }^{1}$, and azziz baidada ${ }^{1}$ \\ ${ }^{1}$ Université Mohammed V de Rabat
}

November 16, 2020

\section{Introduction :}

The transverse vaginal septum or vaginal septum is a rare abnormality of the female genital tract with an incidence of between $1 / 2100$ and $1 / 7200^{1}$. The most common etiology is a defect in the fusion and/or channelling of the urogenital sinus and Mullerian conductors ${ }^{2}$. The transverse vaginal septum can develop anywhere in the vagina, and its most common locations are in the lower part of the vagina according to the latest publications, so $72 \%$ of the septums are in the lower part of the vagina, $22 \%$ in the central part and $6 \%$ in the upper part of the vagina ${ }^{3}$. These septa are usually no more than $1 \mathrm{~cm}$ thick and usually have an eccentric perforation which allows for vaginal discharge. These structural obstacles can completely obstruct the vagina and can cause haematocolpos associated with cyclic pelvic pain shortly after menarche in adolescent girls. Haematocolpos is defined as an accumulation of menstrual blood in the vaginal cavity ${ }^{4}$. The diagnosis of a vaginal septum is based on a careful clinical gynaecological examination and especially on ultrasound scan via the abdomen or transrectal or even transperineal ultrasound and in more complex cases an MRI scan. The treatment is surgical and should be carried out as early as possible, as its management after puberty is associated with a high rate of vaginal stenosis ${ }^{5}$.

\section{Clinical case :}

This is a 16 year old patient with a history of congenital right kidney agenesis, she presents for consultation with a cyclic chronic pelvic pain in a primary amenorrhea context. The patient reports that she has never had sex in her life.

The clinical examination found normal secondary sexual characteristics with a sensitivity in the hypogastric area. The vagina examination found a vagina totally obstructed by a transverse septum in the form of a vaginal diaphragm $1 \mathrm{~cm}$ from the hymen (Figure 1). Pelvic and perineal ultrasound found a normal sized uterus with a large haematocolpos of $10^{*} 12 \mathrm{~cm}$ with the presence of a low transverse vaginal septum located $1 \mathrm{~cm}$ thick (Figure 2).

The treatment consisted of making a transverse incision in the centre of the transverse septum of the vagina, draining the hematocolpos (Figure 3) and visualising the cervix. A circumferential excision of the septum was made and the remaining vaginal edges were then sutured by a simple tarring of the entire circumference using 2-0 absorbable suture (Figure 4). A sponge soaked in oestrogen cream was placed in her vagina to prevent stenosis and removed the day after the operation. The patient was followed in our department for 2 years without any recurrence of vaginal stenosis or hematocolpos .

\section{Discussion :}

One of the main causes of haematocolpos is the transverse vaginal septum, this transverse vaginal septum results either from incomplete channelling of the vaginal plate or failure of the parameonephral ducts to meet 
the urogenital sinus ${ }^{6}$. Vaginal septum was first described in 1877 and since then other case series have been published. However, they remain rare due to the low frequency of this anomaly.

The diagnosis of transverse vaginal septum is made either pre-puberty or post-puberty. In pre-pubertal patients, they present a hydrocolpos caused by an obstruction in the drainage of genital secretions produced by hypersecretion of the proximal reproductive glands which respond to maternal hormonal stimulation. In post puberty, the clinical presentation is variable, depending, above all, on whether or not there is a perforation of the septum. If the septum is complete, as in our case, clinically, patient present abdominal pain associated with primary amenorrhoea with the presence of a haematocolpos, haematometry or haematosalpinx depending on the location of the septum. If the septum is incomplete, the diagnosis is more difficult, as it may be asymptomatic with only dyspareunic or infertility symptoms ${ }^{7}$.

The transverse vaginal septum is not a common mullerian abnormality. Similar to an imperforate hymen, it can present a diagnostic challenge, as the symptoms are often not gynecological in nature, e.g. lower abdominal pain, low back pain, chronic constipation ${ }^{8}$, or urinary retention ${ }^{9}$. An obstructive genital anomaly should be routinely sought in all young women with these symptoms associated with primary amenorrhea. An imperforate hymen is easily distinguished from a transverse vaginal septum on physical examination. The bluish appearance with a bulge is often observed between the lips in the case of an imperforated hymen. In addition, slight pressure applied suprapubically causes visible distension of the imperforated hymen. On the other hand, if a transverse septum is present, suprapubic pressure does not cause a visible bulge in the perineum. The thickness and exact location of a transverse vaginal septum is difficult to assess clinically unless a patient is willing to undergo a careful vaginal and/or rectoabdominal examination. Most young women before their first sexual activities do not undergo such an examination without general anaesthesia. Therefore, the thickness and location of the septum is most often assessed by abdominal ultrasound, transperineal or trans-rectal ultrasound or MRI before attempting management ${ }^{10}$.

Very little data is available in the literature on the surgical management of this condition. In the experience of Dennie et al. ${ }^{11}$, the septum should be removed when the girl reaches the age of first menstruation, and surgery is easier if the patient has a haematocolpos before drainage. Williams et al. ${ }^{12}$ describe 46 patients with VSDs treated by 3 different routes: laparotomy abdomino-perineal vaginoplasty, simple vaginal excision and laparoscopic resection of the vaginal wall. Another surgical approach is the Grünberger method, which consists of a cross-shaped incision in the caudal part of the septum and a cross incision in the other part with transverse closure ${ }^{13,14}$.

Van Bijsterveldt et al. ${ }^{15}$ proposed two new techniques for the treatment of the vaginal wall: push and pull techniques. The former requires a combined abdominal-vaginal approach, and is used in patients with a higher risk of restenosis after surgery. The traction technique is reserved for patients with a simple vaginal obstruction. A modification of this technique was performed by Layman et al. ${ }^{16}$ with traction through proximal distension of the vagina using an Olbert balloon catheter to facilitate surgical management and to limit postoperative narrowing of the vagina. Sardesai et al. ${ }^{17}$ described a double cross-plasty/Z-plasty for vaginal wall management after 20 years experience as the best technique compared to other surgical methods.

Vaginal stenosis at the resection site remains the most common complication ${ }^{18}$, postoperative vaginal dilation may help to reduce scarring and stenosis at the surgical site ${ }^{19}$, this postoperative dilation is essential to the success of the procedure. Other less common complications are described after surgery, such as dyspareunia, menstrual irregularities and fertility problems.

Management of the vaginal septum with drainage of the haematocolpos at an early age is necessary to preserve fertility and reduce the risk of endometriosis. Therefore, these patients and their parents need to be informed about these potential long-term complications and the importance of regular follow-up ${ }^{19,20}$.

\section{Conclusion :}

The transverse vaginal septum remains a rare anomaly of the female genital tract, the reasons for its discovery are extremely variable according to its shape and location. Haematocolpos remains the main consequence 
of these septums, the managementis essentially based on surgery while taking into account the risks of postoperative stenosis and the repercussions on the upper genital tract.

\section{Figures :}

Figure 1: Transverse septum obstructing the vagina

Figure 2: Suprapubic ultrasound image showing the haematocolpos in the form of a large anechogenic mass compressing the bladder.

Figure 3: haematocolpos drainage after incision of the transverse spetum of the vagina

Figure 4: the final result obtained after suturing the edges of the incision

\section{Authors'contributions}

KE made substantial contributions to conception and design, acquisition of data, analysis and interpretation of data; he has been involved in drafting the manuscript and revising it critically for important intellectual content. AL made substantial contributions to interpretation of data and she has beeninvolved in drafting the manuscript and revising it critically for important intellectual content. AB and AL made substantial contributions to conception and design and acquisition of data; they has been involved in drafting the manuscript.

All authors read and approved the final version of the manuscript

\section{Funding}

There are no funding sources to be declared.

\section{Availability of data and materials}

The datasets used and/or analyzed during the current study are available from the corresponding author on reasonable request.

\section{Ethics approval and consent to participate}

Ethics approval has been obtained to proceed with the current study. Consent to participate not applicable.

\section{Consent for publication}

Written informed consent was obtained from the patient's parent/guardian for publication of this case report and any accompanying images. A copy ofthe written consent is available for review by the Editor-in-Chief of this journal.

\section{Competing interests}

The authors declare that they have no competing interests.

\section{Références :}

1. Saks EK, Vakili B, Steinberg AC. Primary amenorrhea with an abdominal mass at the umbilicus. J Pediatr Adolesc

Gynecol 2009;22(1):e1-3.

2. Breech LL, Laufer MR. Müllerian anomalies. Obstet Gynecol Clin North Am 2009;36(1):47-68.

3. Williams CE, Nakhal RS, Hall-Craggs MA, Wood D, et al. Transverse vaginal septae: management and long-term outcomes. BJOG 2014;121(13):1653-8.

4. Deligeoroglou E, Iavazzo C, Sofoudis C, Kalampokas T, Creatsas G. Management of hematocolpos in adolescents with transverse vaginal septum. Arch Gynecol Obstet 2012;285(04):1083-1087. Doi: 10.1007/s00404011-2114-4 
5. Rock JA. Surgery for anomalies of the Müllerian ducts. En Rock JA, Thompson JD, eds. Telinde's operative gynecology. 8th ed. Philadelphia: Lippincott-Raven; 1997:687-729.

6 . Rock JA, Zacur HA, Dlugi AM, JonesHWJr, TeLinde RW. Pregnancy success following surgical correction of imperforate hymen and complete transverse vaginal septum. Obstet Gynecol 1982;59(04):448-451 8 Deligeoroglou

7. Paredes Esteban RM, Ocaña Losa JM, Pizarro de Celis F, Gutiérrez Cantó M, et al. Síndrome de McKusickKaufman: Aportación de cinco nuevos casos, incluido un varón. An Esp. Pediatr 1996;44(5):493-5.

8. Wang W, Chen MH, Yang W, Hwang DL. Imperforate hymen presenting with chronic constipation and lumbago: report of one case. Acta Paediatr Taiwan 2004;45:340-2.

9. Dane C, Dane B, Erginbas M, Cetin A. Imperforate hymen - a rare cause of abdominal pain: two cases and review of the literature. J Pediatr Adolesc Gynecol 2007;20:245-7.

10. Miller R, Breech L. Surgical correction of vaginal anomalies. Clin Obstet Gynecol 2008;51:

$223-36$

11. Dennie J, Pillay S, Watson D, Grover S. Laparoscopic drainage of hematocolpos: a new treatment option for the acute management of a transverse vaginal septum. Fertil Steril 2010;94(05): 1853-1857. Doi: 10.1016/j.fertnstert.2009.09.041

12. Williams CE, Nakhal RS, Hall-Craggs MA, et al. Transverse vaginal septae: management and long-term outcomes. BJOG 2014;121 (13):1653-1658. Doi: 10.1111/1471-0528.12899

13. Garcia RF. Z-plasty for correction of congenital transferse vaginal septum. Am J Obstet Gynecol 1967;99(08):1164-1165. Doi:10.1016/0002-9378(67)90357-2

14. Blanton EN, Rouse DJ. Trial of labor in women with transverse vaginal septa. Obstet Gynecol 2003;101(5 Pt 2):1110-1112

15 van Bijsterveldt C, Willemsen W. Treatment of patients with a congenital transversal vaginal septum or a partial aplasia of the vagina. The vaginal pull-through versus the push-through technique. J Pediatr Adolesc Gynecol 2009;22(03):157-161. Doi: 10.1016/j.jpag.2008.02.008

16. Layman LC, McDonough PG. Management of transverse vaginal septum using the Olbert balloon catheter to mobilize the proximal vaginal mucosa and facilitate low anastomosis. Fertil Steril

2010;94(06):2316-2318. Doi: 10.1016/j.fertnstert.2009.12.061

17. Loscalzo IL, Catapano M, Loscalzo J, Sama A. Imperforate hymen with bilateral hydronephrosis: an unusual emergency department

diagnosis. J Emerg Med 1995;13(03):337-339

18 .Rink Richard C, Kaefer Martin. Surgical management of disorders of sexual differentiation, cloacal malformation and other abnormalities of the genitalia in girls. In: Wein AJ, editor. Campbell-Walsh urology. 9th ed. Philadelphia: Saunders; 2007.

19. Gupta Ridhima, Bozzay Joseph D, Williams David L, DePond Robert T, Gantt Pickens A. Management of recurrent stricture formation after transverse vaginal septum excision. Case Rep Obstet Gynaecol 2015. http: //dx.doi.org/10.1155/2015/975463.

20 . Rock JA, Zacur HA, Dlugi AM, Jones Jr HW, TeLinde RW. Pregnancy success following surgical correction of imperforate hymen and complete transverse vaginal septum. Obstet Gynaecol 1982;59(4):448e51. 


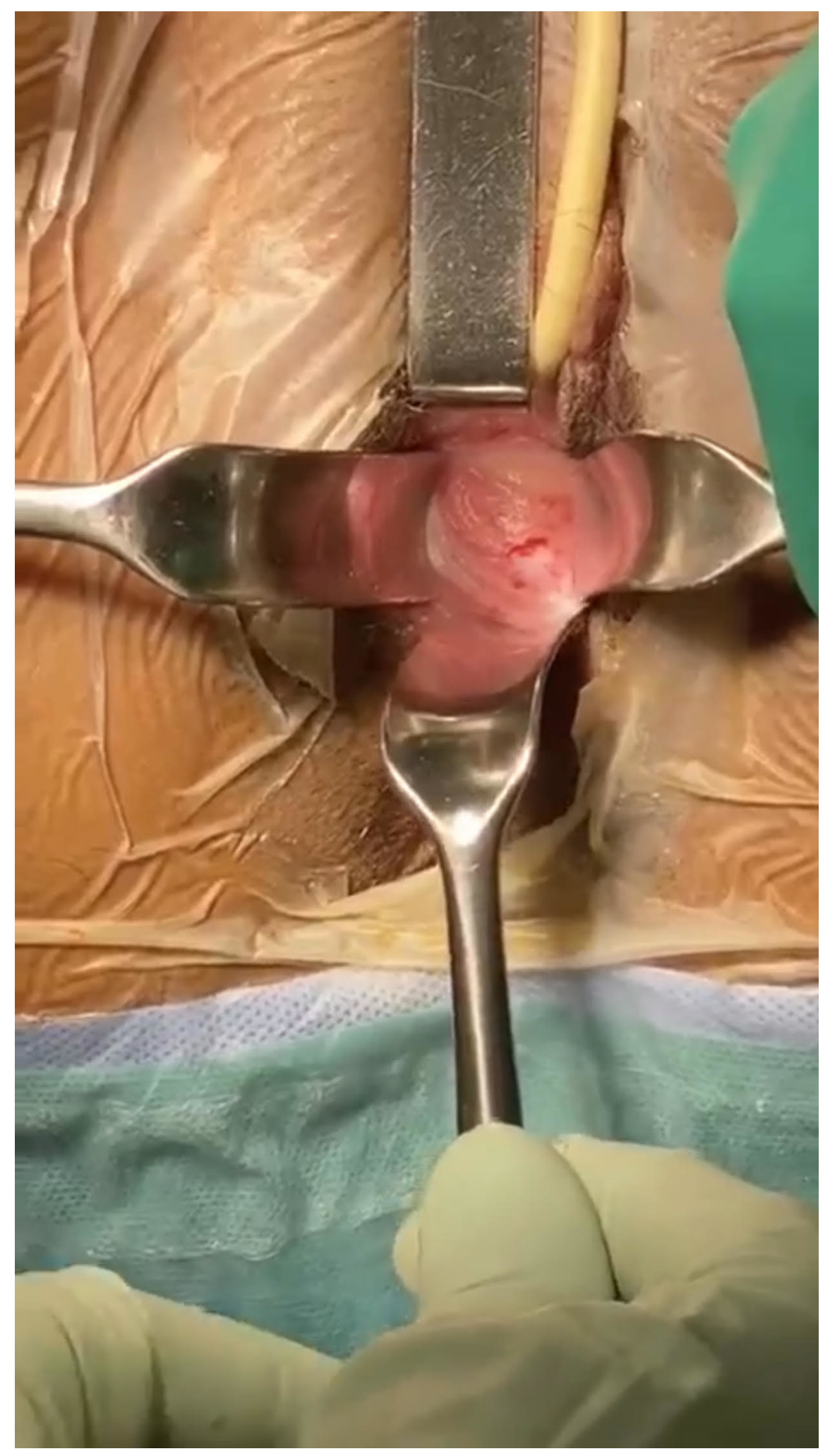




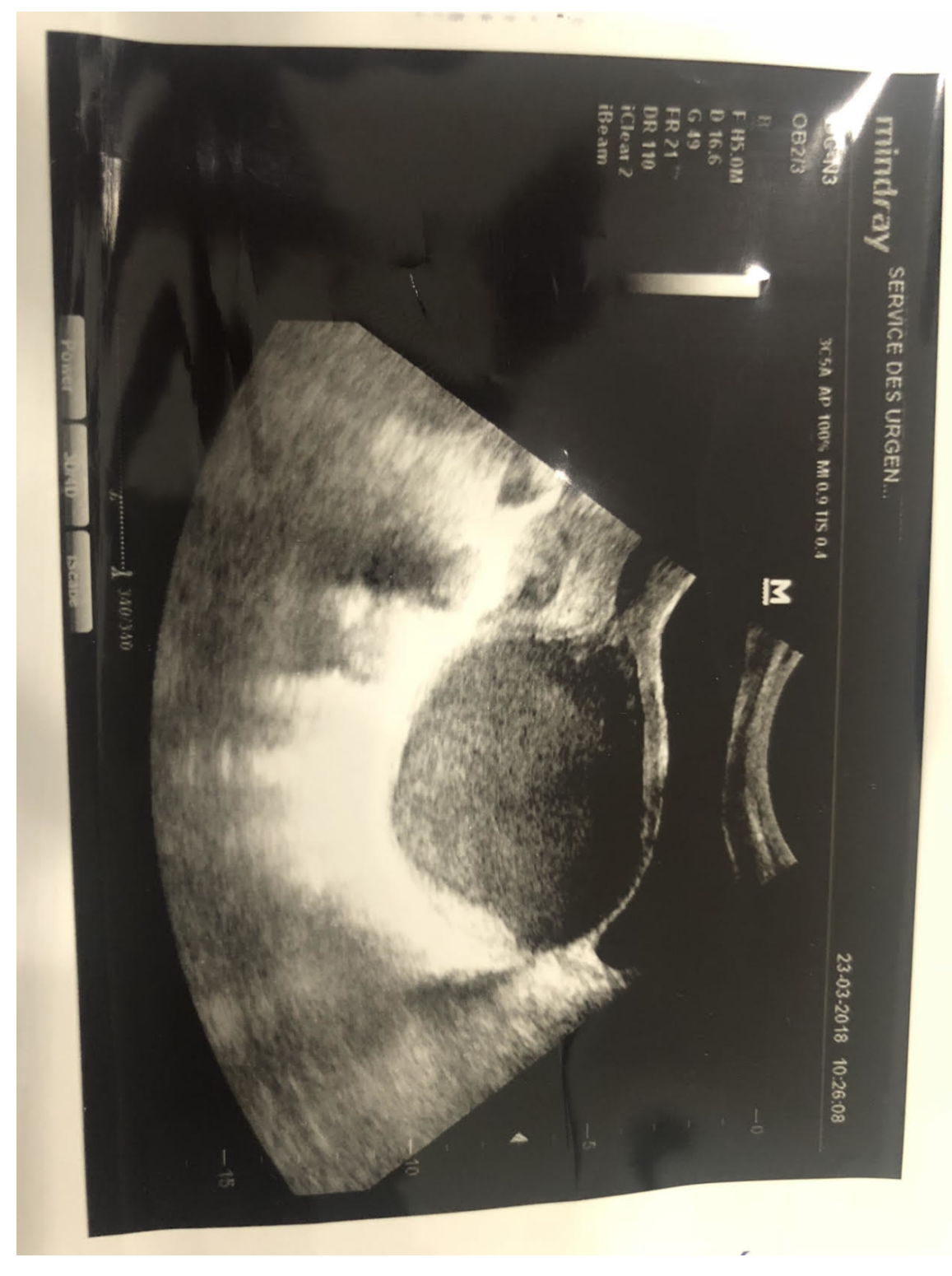




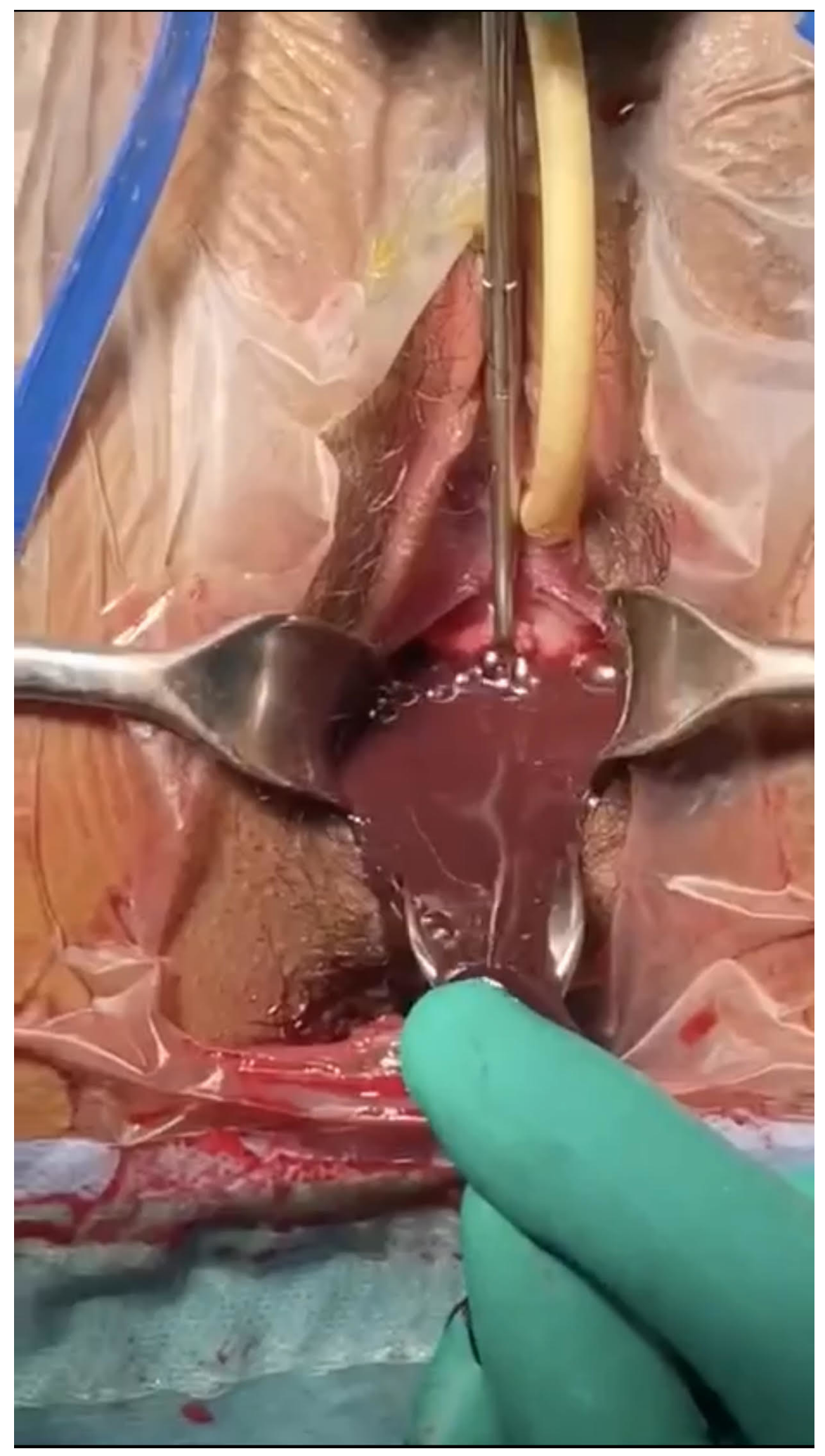




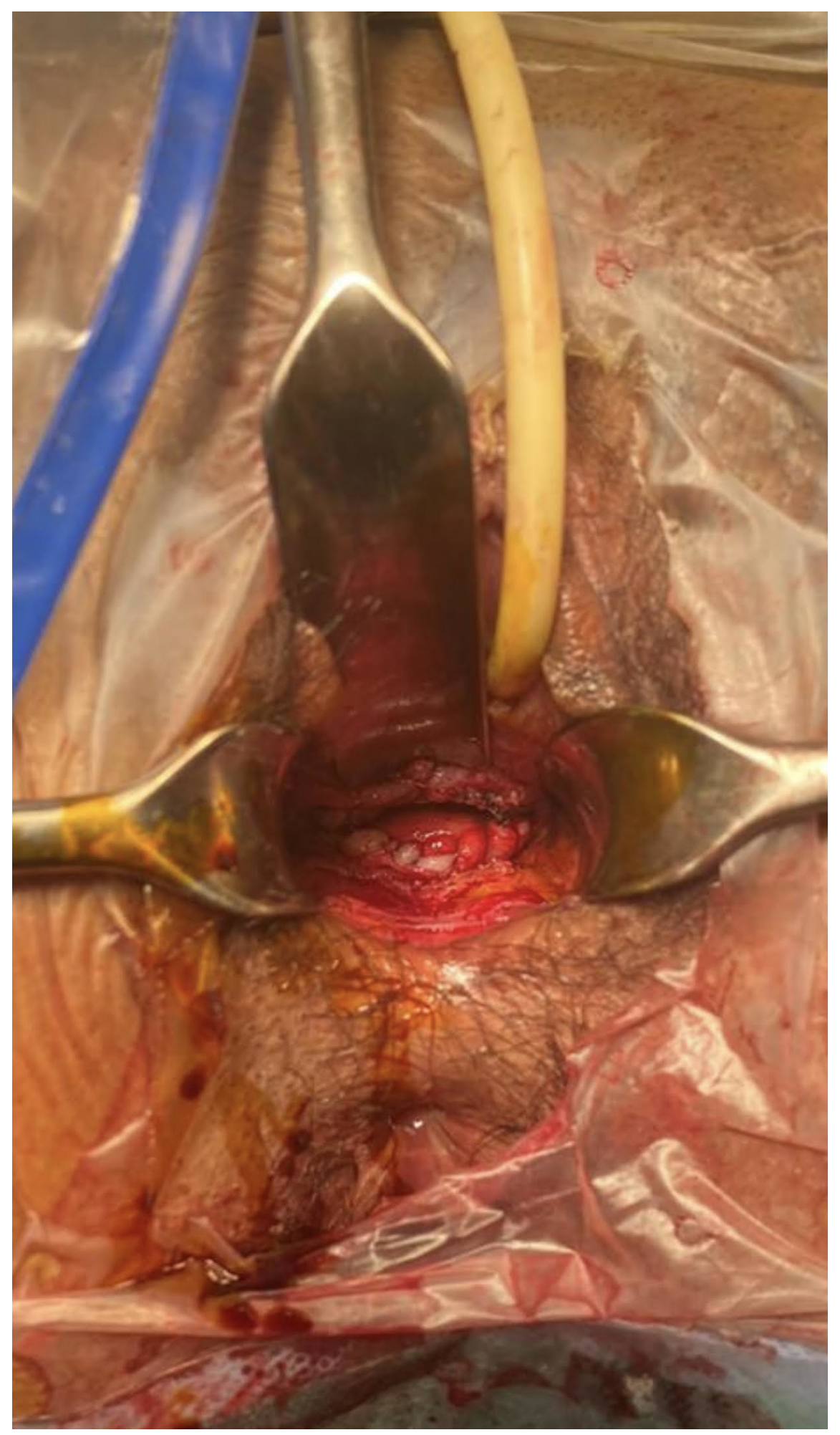

